\section{Water in Sport: Northern Grampians Shire Council}

\section{Introduction}

During 2018-2020, Northern Grampians Shire Council partnered with VicHealth to improve access to water and create healthy drink environments in Stawell Sports \& Aquatic Centre.

\section{Objectives}

$\rightarrow$ Increase the promotion and supply of water and reduce the availability and supply of sugary drinks in our community sports and recreation facilities. (>50\% GREEN drinks like water and <20\% RED sugary drinks)

$\rightarrow$ Strengthen council policies and practices to enable longer-term changes to healthy drinks environments across council-owned sport and recreation facilities.
The Healthy Choices: food and drink classification guide uses a traffic light system to classify foods and drinks as:

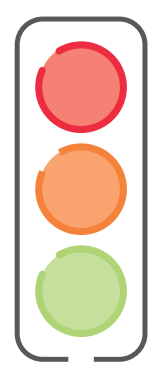

RED: Limit intake

AMBER: Choose carefully

GREEN: Best choice

\section{Why}

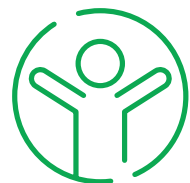

Northern Grampians Shire

Council has a commitment

to supporting the health and

wellbeing of our community.

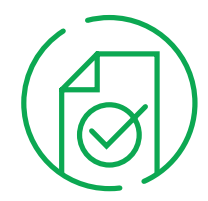

The environments in which we live, work, learn, and play are key drivers of the types of food and drink we consume. Local governments can play a key role in implementing policies and practices to improve local food and drink environments.

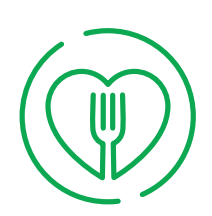

There is community support and expectation for healthy food and drinks $-75 \%$ of customers surveyed from all Water in Sport councils believed that sport and recreation facilities should promote healthy eating.

\title{
Outcomes
}

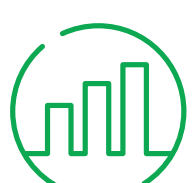

Overall, availability of 'GREEN' drinks increased from $22 \%$ to $74 \%$ of all drinks and 'RED' drinks decreased from $75 \%$ to $14 \%$ of all drinks.

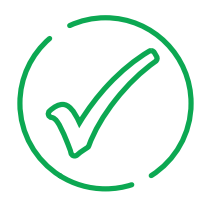

Stawell Sports \& Aquatic Centre met the Healthy Choices Guidelines for drinks.

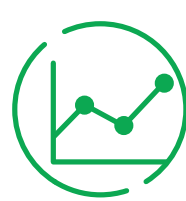

Stawell Sports \& Aquatic Centre sales of 'GREEN' drinks increased $10 \%$ and sales of 'RED' drinks decreased by $27 \%$ between May 2018 and February 2020.

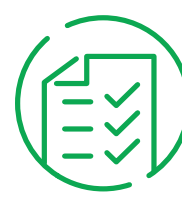

Stawell Sports \& Aquatic Centre had no change in total drinks revenue.

\section{Recommendations for creating healthy food retail environments in your community}

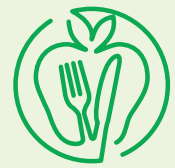

Use the VicHealth toolkit for creating healthy food and drink environments in community food retail outlets.

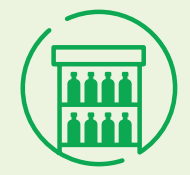

Start by trialing a small 'quick win' which is easy to implement and unlikely to cause revenue loss, such as rearranging the fridge to put 'GREEN' drinks at eye-level.

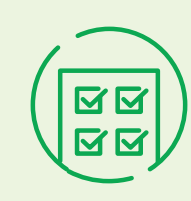

Develop healthy food environment policies and procedures for councils and facilities.
Contact the Healthy

Eating Advisory

Service for practical

implementation support. 